\title{
LAS ONG MICROFINANCIERAS PERUANAS: ¿SIGUEN MANTENIENDO SU MISIÓN SOCIAL?
}

\author{
POR \\ Raquel MARBÁN FLORES ${ }^{1}$
}

\section{RESUMEN}

En los últimos años el crecimiento del sector microfinanciero ha sido considerable, hecho que ha venido en paralelo con la aparición de marcos reguladores que se marcan como objetivo impulsar la expansión del sector. Es el caso de Perú, país en donde, sin embargo, varias ONG han decidido no convertirse en instituciones reguladas argumentando que esto las alejaría de la función social para la que fueron creadas. En un mercado competitivo, con un marco legislativo que impulsa la formalización de las instituciones microfinancieras, cuál sea el papel de las ONG es una cuestión que merece estudio. Es el objetivo de este artículo, que analiza la función social de las ONG peruanas que no se han acogido a la regulación. Para ello, un número de indicadores (atención a la mujer, crédito medio, destino del crédito, entre otros) son analizados. Estos indicadores son usados para evaluar la función social que llevan a cabo estas ONG y para conjeturar sobre su futuro en este entorno cambiante.

Palabras clave: microfinanzas, microcréditos, tercer sector.

Claves Econlit: G21, Q14, R11.

\begin{abstract}
In recent years, the growth of the microfinance sector has been significant. Either as a cause or as a consequence, some governments have decided to make it part of the financial system adapting regulatory frameworks to allow the sector to continue to expand as the number of formal institutions increases. It is the case in Peru where many NGOs have decided not to become regulated, arguing that this change could leave them to move away from the
\end{abstract}

\footnotetext{
${ }^{1}$ Facultad de CC. Económicas y Empresariales. Universidad Complutense de Madrid. Dirección de correo electrónico: rmarban@ccee.ucm.es.

REVESCO No 123 - Primer Cuatrimestre 2017 - ISSN: 1885-8031 - www.ucm.es/info/revesco

http://dx.doi.org/10.5209/REVE.52987

Fecha de recepción: 13/01/2014

Fecha de aceptación: 17/06/2016
} 
social aims for which they were created. In an increasingly competitive marketplace, where the legal framework encourages the regulation of microfinance institutions, there appears to be a need to study the potential future role of NGOs in the sector. In consideration of this question, this paper attempts to analyse the social role of those NGOs that have decided not to become regulated institutions. In this study a number of social indicators are analysed; these include the number of female clients, average loan amount and how loans are used, among others. These indicators will be used to attempt to evaluate the social role of unregulated NGOs and their prospects in this new context.

Keywords: Microfinance, microcredit, third sector.

\section{INTRODUCCIÓN}

El sector microfinanciero ha demostrado ser una importante herramienta en la lucha contra la pobreza, desempeñando un papel clave en la inclusión social y financiera especialmente en los países en desarrollo (Khalily et al., 2000; Pogge, 2002; Aghion y Morduch, 2005; Jeppesen, 2005; Agbeibor, 2006; Caniels et al., 2006; Helms, 2006; Diniz et al., 2008; Roodman y Morduch, 2009; Chu, 2010; Marbán Flores, 2011; Syed, 2012). Sin embargo, y a pesar del éxito demostrado, actualmente este sector podría estar alejándose del fin social para el que fue creado, dejando de otorgar créditos a la población más pobre para atender a una "capa intermedia" de pobreza, es decir, personas que están excluidas del sector financiero pero que no se encuentran entre los más necesitados (CGAP, 2001; Robinson, 2001; Alves y Soares, 2006; Goldberg y Karlan, 2006; Marbán Flores, 2008).

Originariamente, en el sector microfinanciero operaban exclusivamente organizaciones sin ánimo de lucro y cooperativas con fuerte orientación social. Posteriormente fueron llegando al sector nuevos agentes tales como bancos comerciales, que incluyen como parte de su actividad los servicios microfinancieros, y otros modelos de IMF (Instituciones Microfinancieras) creadas para atender a personas excluidas financieramente pero con ciertos recursos económicos. Este fenómeno no se ha producido de igual manera en todos los países. Por ejemplo, en América Latina comenzó en la década de los ochenta del siglo pasado (Marulanda y Otero, 2005).

Estos nuevos agentes, especialmente los bancos comerciales, han visto en las microfinanzas una oportunidad para crecer (CGAP, 2005), oportunidad que se reforzaría con una regulación que permitiera nuevas actividades y propiciara el desarrollo del sector. Los 
gobiernos han respondido a esta demanda $\mathrm{y}$ en aquellos países donde el sector microfinanciero ha alcanzado cierta madurez se han elaborado marcos reguladores específicos. Los marcos reguladores pretenden poner las condiciones para que el volumen de los servicios financieros prestados y el número de clientes atendidos se incrementen (Christen et al., 2003).

Algunos autores ven en la regulación una gran oportunidad para que las organizaciones no gubernamentales (ONG) se transformen en nuevas entidades jurídicas, hecho que les permitiría acceder a capital (Khandler, 2005), ganar legitimidad, aumentar el número de empleados y clientes, permitir la entrada de nuevos socios, y ofrecer servicios financieros diferentes de los préstamos (Khandler, 2005; Lauer, 2008). Otros autores, por el contrario, temen que las ONG transformadas pasen a atender a una población "menos pobre" para poder ser sostenibles (Mayoux, 2001; Goldberg, 2005; Lafourcade et al., 2005; Mersland and Oystein, 2010). Su argumento es que la preocupación por la rentabilidad puede llevar a las organizaciones a abandonar segmentos de mercado menos rentables a corto plazo o reducir servicios como la educación, el asesoramiento o la atención sanitaria, que han venido formando parte de la acción social del microcrédito pero que, obviamente, tienen un efecto negativo inmediato en la cuenta de resultados de la entidad (de la Torre et al., 2007; Lewis, 2008; Lauer, 2008). Se pueden apreciar ciertas ventajas a la regulación tales como que permiten captar recursos a través de los depósitos públicos, se produce una mayor estandarización de los informes financieros y esto repercute sobre una mayor transparencia y reducción del riesgo moral (Thankon, 2004). A esto hay que añadir que los argumentan a favor de la regulación prudencial consideran que pueden prevenir el riesgo de un posible aprovechamiento de los inversionistas y otros agentes de mercado, especialmente entre las instituciones capaces de tomar depósitos del público (Chávez y González Vega, 1994).

En América Latina, uno de los pioneros en la creación de un marco regulador adaptado al sector microfinanciero fue Perú (Microscopio BID, 2012). En la década de los noventa se elaboró un marco regulador que pretendía impulsar el sector y lo ponía bajo la supervisión de la autoridad bancaria peruana (SBS, Superintendencia de Banca y Seguros y el Banco Central de Reservas de Perú). Como en otros lugares, las reacciones fueron también encontradas: lo que podía parecer una gran ventaja en el contexto peruano, en donde el sector es muy competitivo y las ONG deben pagar impuestos sobre intereses devengados, fue visto por algunas organizaciones como una dificultad que les podría desviar de su misión social. 
Dos décadas después de la aparición de nuevos agentes y de los primeros pasos de la regulación microfinanciera siguen operando en Perú 13 ONG que no se han transformado en instituciones reguladas (Mix market ${ }^{2}$, 2013; COPEME, 2012), en algunos casos por su reducida dimensión, en otros por considerar que transformarse puede alejarles de su misión social e incluso existen organizaciones que deseaban transformarse pero no obtuvieron la pertinente autorización. En este contexto, parece tener sentido analizar si las ONG que no se transformaron en instituciones reguladas han mantenido su orientación social y, por tanto, verificar si su decisión ha estado justificada.

Es el objetivo de este artículo, mediante el análisis de una serie de indicadores, evaluar la orientación social de las ONG microfinancieras no transformadas comparándolas con la actividad de las transformadas. Para ello el presente trabajo se articula de la siguiente manera: en el apartado 2 se analiza el sector microfinanciero en Perú; en el apartado 3 se estudia el papel de las ONG peruanas que operan en el sector; en el apartado 4 se presentan algunos indicios que permiten articular un discurso sobre la realidad actual de las ONG y su papel social comparándolo con las EDPYME ${ }^{3}$; las conclusiones cierran el trabajo.

\section{ORIGEN DE LAS MICROFINANZAS}

El origen de las microfinanzas se remonta a la década de los 70 cuando en Bangladesh el profesor Yunnus, precursor de los microcréditos, empieza a conceder pequeños créditos a personas pobres sin ningún tipo de garantía (Armendáriz y Morduch, 2005). Poco a poco esta experiencia se fue consolidando hasta crear una de las instituciones microfinancieras más importantes del mundo: el Grameen Bank. Hoy en día es un referente en el sector microfinanciero (Fernández, 2006 en Galindo y Cuesta (Coord.); Lacalle, 2008).

Prácticamente al mismo tiempo en América Latina surgen otras experiencias similares. Debemos destacar el papel de Acción Internacional que en 1973 empezó a otorgar microcréditos en Recife (Brasil). Con el tiempo esta experiencia se ha ido extendiendo a la mayoría de los países de la región.

Estos pequeños créditos otorgados en Asia y América Latina compartían algunas características comunes. Una de ellas es que su principal objetivo era atender a la población

\footnotetext{
${ }^{2}$ MIX es la principal fuente de datos y análisis sobre microfinanzas. MIX provee información de desempeño sobre IMF, donantes, redes y proveedores de servicios dedicados a satisfacer las necesidades del sector financiero para clientes de bajos ingresos.

${ }^{3}$ EDPYME son las instituciones reguladas transformadas de ONG.
} 
más pobre y vulnerable. En este sentido las instituciones no solicitaban ningún aval o colateral que respondiera del crédito en caso de impago. Otra característica es que en la mayoría de los casos estas instituciones se orientaban a las mujeres que vivían en el medio rural, por considerar que era la población más vulnerable. Además, estos créditos tenían como objetivo principal el autoempleo a través de la creación de pequeñas empresas.

Con el paso del tiempo muchas de las instituciones microfinancieras (IMF) detectaron que la población a la que atendían tenía necesidades que iban más allá de un simple crédito (Banerjee and Duflo, 2010). En este sentido el concepto de los microcréditos se fue ampliando hasta lo que hoy se conoce como microfinanzas. Este nuevo concepto incluía otros servicios microfinancieros tales como los microleasing, los microseguros, los pequeños ahorros, etc. En esta línea algunas IMF, especialmente las del tercer sector, han ido más allá y están dedicando parte de sus recursos a la formación de sus beneficiarios en temas básicos como: el emprendimiento, la educación infantil o la sanidad más elemental. Sin embargo, este no ha sido el camino que han seguido todas las IMF porque muchas de ellas están sometidas a la presión de los donantes o a la regulación institucional que les exigen ser autosostenibles. En efecto, son muchos los ejemplos de las IMF que han tenido que centrarse en la sostenibilidad (o rentabilidad) dejando a un lado aspectos sociales tales como la orientación hacía la población más desfavorecidos (Khalily, 2000; Navajas, 2006; Marbán Flores y De Pablo Diez, 2012).

\section{EL CASO PARTICULAR DEL SECTOR MICROFINANCIERO EN PERÚ}

El sector microfinanciero peruano es uno de los más desarrollados y dinámicos de América Latina y entre los diez países mejores del mundo que pueden seguir ampliando el acceso de los servicios financieros a la población más desatendida (Microscopio del BID, $2014)^{4}$. Como prueba de su dinamismo, en el periodo que va de junio de 2011 a junio de 2012 el montante de los créditos directos otorgados a microempresas se había incremento en un $14 \%$ (PCR, 2012).

De acuerdo con los últimos datos disponibles (SBS, 2013-2014; COPEME, 2014) en el sector operan una Corporación Financiera de Desarrollo (COFIDE), Cooperativas de Ahorro y Crédito (COOPAC), Cajas Rurales de Ahorro (CRAC), Cajas Municipales de

\footnotetext{
${ }^{4}$ Pese a todo, la penetración de mercado del sector microfinanciero puede considerarse todavía baja, con una cartera de prestatarios pobres atendidos del 14\% (Mix Market, 2008).
} 
Ahorro y Crédito (CMAC), sociedades financieras, bancos comerciales, Entidades de Desarrollo de la Pequeña y Microempresa (EDPYME) y ONG.

- La Corporación Financiera de Desarrollo (COFIDE) es el único banco de desarrollo (de los seis que existían) que sobrevivió a la crisis de la década de los noventa. Es una empresa autónoma de economía mixta perteneciente en un 98,56\% al Estado Peruano y en el resto a la Corporación Andina de Fomento (CAF). Actúa como entidad "de segundo piso" otorgando créditos a entidades financieras reguladas orientadas a la microempresa y a la pequeña empresa (Mix market, 2012).

- Las Cooperativas de Ahorro y Crédito (COOPAC), propiedad de los socios, ofrecen servicios a sus asociados en forma de depósito y acceso al préstamo. Existen 165 COOPAC que sirven aproximadamente a 700.000 socios en 21 regiones del país aunque sólo 112 están autorizadas a captar ahorro de los socios. Resulta difícil precisar cuál es el número de ellas que están dedicándose al sector microfinanciero. Están agrupadas en la Federación Nacional de Cooperativas de Ahorro y Crédito. Esta Federación es la encargada de la supervisión de las COOPAC (COPEME, 2014).

- Las Cajas Rurales de Ahorro y Crédito (CRAC) fueron creadas en la década de los noventa tras el cierre del Banco Agrario. Tienen la capacidad de captar ahorro del público y están especializadas en otorgar financiación a las medianas, pequeñas y micro empresas en el ámbito rural. En el año 2004 había 15 CRAC; actualmente son 9 las que operan en el sector microfinanciero en Perú (SBS, 2013; COPEME, 2014).

- Las Cajas Municipales de Ahorro y Crédito (CMAC) fueron creadas en la década de los ochenta (con el apoyo de la cooperación alemana) para atender a la población excluida del sistema financiero tradicional prestando servicios de ahorro y crédito. Estas instituciones eran originariamente propiedad de los gobiernos municipales o provinciales y se especializaron en la financiación de la pequeña y microempresa y del ahorro rural. En el año 2004 había 14 CMAC; el número se ha reducido a 12 (COPEME, 2014; SBS, 2013).

- Las sociedades o entidades financieras otorgan créditos, facilitan depósitos y en algunos casos ofrecen seguros y otros servicios como transferencia de dinero. Estas entidades han estado sometidas a procesos de transformación como sucedió con 
Financiera Solución ${ }^{5}$ que fue absorbida por el Banco de Crédito de Perú (BCP). Existen 10 sociedades financieras en Perú (Mix market, 2013).

- Los bancos operan en la industria microfinanciera peruana desde la década de los noventa (Portocarrero, 2000). Entre los más importantes se pueden citar Banco del Trabajo y Mibanco. El Banco de Trabajo estaba orientado a conceder créditos de consumo a personas (no empresas) de estrato económico medio-bajo; tras su adquisición por Scotiabank Perú se ha transformado en la entidad financiera llamada CrediScotia Financiera. Mibanco surgió en 1998 en Perú sobre la base de la experiencia de Acción Comunitaria del Perú ${ }^{6}$; su número de clientes ha crecido significativamente en los últimos años pasando de poco más de 150.000 en el año 2005 a casi 500.000 en el año 2012 (Mix market, 2013; COPEME, 2014).

- Las Entidades de Promoción de la Pequeña y Mediana Empresa (EDPYME) se crearon en 1994 por la resolución SBS no 897-94 que permitía la formalización de las ONG en entidades microfinancieras. Muchas ONG se transformaron en instituciones reguladas para obtener ventajas como poder captar ahorros o estar exentas del pago del Impuesto General de Ventas en los intereses devengados sobre sus préstamos, obligación que deben satisfacer las ONG en Perú (Ebentreicho, 2005). En la actualidad, otorgan créditos similares a los que otorgan las CMAC (créditos microempresa, de consumo, comerciales, hipotecarios, etc.) pero no están autorizadas a captar ahorros del público ${ }^{7}$. Para evitar esta restricción y ampliar sus operaciones, algunas de estas instituciones han realizando un proceso de conversión en sociedades financieras. Como consecuencia de este proceso el número de EDPYME se ha reducido de 18 en el año 2004 a 8 en el año 2014 (COPEME, 2014).

- Las ONG que no se han transformado en EDPYME no están supervisadas por la SBS y por tanto, no están autorizadas a captar ahorros del público. En la actualidad existen $13 \mathrm{ONG}^{8}$ (COPEME, 2014) que dan asistencia a la población más desfavorecida a través de las microfinanzas y de servicios adicionales en los ámbitos de la

\footnotetext{
${ }^{5}$ Como empresa financiera centraba su actividad en el crédito al consumo y crédito a PYME.

${ }^{6}$ Acción Comunitaria del Perú era una ONG con 42 años de experiencia en atención a la pequeña y mediana empresa.

${ }^{7}$ Pueden, sin embargo, emitir tarjetas de crédito siempre que lo autorice la SBS (Microscopio BID, 2007).

${ }^{8}$ Puede existir un número superior de ONG que operen en microfinanzas de forma residual. El dato aportado se basa en la información de Mix Market y la información de ASOMIF (publicada en http://www.asomifperu.com/)
} 
capacitación, la educación o la salud. Comparativamente, estas organizaciones no tienen un gran peso en el sector microfinanciero peruano dado que atienden a unos 200.000 clientes frente los tres millones y medio de prestatarios que tiene el sector en Perú 9 . Compárese esta cifra con la de, por ejemplo, CrediScotia Financiera que tiene una cartera de clientes superior a los 700.000, aunque obviamente no es fácil determinar cuántos de sus clientes pueden considerarse pobres ${ }^{10}$ (Mix market, 2015).

\section{LA REALIDAD DE LAS ONG MICROFINANCIERAS EN PERÚ}

No se puede obviar el importante papel social que las ONG desempeñan atendiendo a la población más vulnerable cubriendo las necesidades básicas y ofreciendo acceso a formación, servicios sociales o asistencia sanitaria (Clark, 1991; Fiszbein y Lowden, 1999; Harper, 2002, Yun, 2011). En el sector microfinanciero, las ONG, en general, siguen esta línea de actuación y atienden a prestatarios de muy bajos ingresos. Obviamente, este mayor alcance (como se denomina en la terminología microfinanciera) puede implicar la "no eficiencia” de estas ONG (Roy y Chowdhury, 2009).

Es el caso en Perú, donde las ONG, que hasta ahora habían sido relativamente eficaces en la atención a segmentos rurales por estar ubicadas mayoritariamente en estas zonas, no tienen asegurada su supervivencia. La enorme competencia y la creciente demanda del sector microfinanciero está haciendo que instituciones que operaban sólo en zonas urbanas busquen nuevos segmentos de mercado en zonas rurales con menor competencia. Otra causa que frena el crecimiento de las ONG es la imposibilidad de captar ahorro, lo que genera una fuerte dependencia de la financiación externa (en forma de donaciones, subvenciones o, financiación de bancos comerciales). Además, las ONG peruanas se enfrentan a una desventaja adicional, y es que están obligadas a pagar impuestos sobre los intereses devengados. A todo lo anterior hay que añadir que sus tasas de eficiencia operativa son peores que las que presentan las IMF reguladas.

A pesar de todas estas limitaciones existen, como se ha indicado, 13 ONG que operan en la industria microfinanciera peruana y no se han transformado en IMF reguladas. La motivación no es la misma en todos los casos. Algunas de ellas mantienen firme su deseo de

\footnotetext{
${ }^{9}$ El número total de clientes prestatarios en el sector microfinanciero peruano es de 3.600.000 y el número de clientes de depósitos asciende a 3.500.000 clientes (Mix Market, 2013).

${ }^{10}$ Las entidades formales tienen 7,4 millones de prestatarios. Si el número de pobres de entre el total fuera sólo del 5\%, eso significaría que llegan a 371.000 personas en situación de pobreza, cifra superior a los 192.000 que atienden las ONG.
} 
no convertirse en IMF pues consideran que ello les desviaría de su orientación social. Otras, en cambio, estaban interesadas en transformarse pero no han sido autorizadas para hacerlo (es el caso de Prisma) o están en proceso de transformación (como es el caso de Fondesurco) ${ }^{11}$.

\section{ASPECTOS METODOLÓGICOS Y ANÁLISIS DE ALGUNOS INDICADORES SOCIALES EN LAS ONG Y LAS EDPYME}

El presente trabajo pretende explicar qué trayectoria han seguido las ONG que decidieron no transformarse en reguladas. Para llevar a cabo este análisis se verificarán algunos indicadores o indicios que permitan evaluar su orientación social tanto en las ONG como en las instituciones que se han transformado en reguladas (EDPYME) ${ }^{12}$.

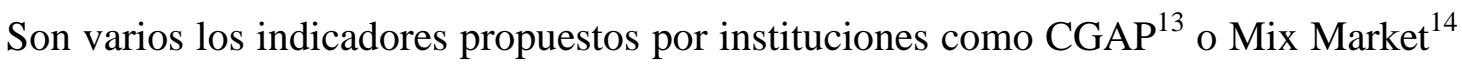
para medir el impacto social de una institución microfinanciera. Sin embargo, no siempre es fácil acceder a estos datos. Es por ello que para el presente trabajo se han seleccionado aquellos cuya información está accesible en fuentes fiables y pueden ser comparados (las ONG y las EDPYME). En este sentido, se han seleccionado cinco indicios que se estudiarán con mayor detalle en los subapartados siguientes pero que, de forma resumida, se enumeran a continuación:

a) Atención a la mujer. Las organizaciones pioneras del microcrédito se centraron en la atención a la mujer por considerar que ésta era una población altamente vulnerable. De hecho, en su origen algunas ONG llegaron a tener porcentajes de prestatarios mujeres superiores al 90\%. Hoy se estima que el sector microfinanciero atiende a más de 140 millones de mujeres en todo el mundo lo que supondría alrededor de un $75 \%$ de los clientes totales (Daley-Harris, 2011).

b) Crédito promedio. Este es el indicador más usado por los inversores y donantes del sector microfinanciero para evaluar la orientación de las IMF hacía los segmentos de población más pobres (Shreiner, 2002, Cull et al., 2007). Para ellos la desviación de la

\footnotetext{
${ }^{11}$ Para que las ONG se transformen en instituciones reguladas (EDPYME) deben presentar cierto nivel de solvencia y rentabilidad exigido por el Banco Central de Perú. No se ha podido encontrar los criterios concretos requeridos por el Banco Central, se tiene constancia de ello por las conversaciones mantenidas con agentes del sector.

${ }^{12}$ Importantes organizaciones como CGAP (2001) consideran que las instituciones que proporcionan los servicios microfinancieros deben guiarse por cuatro principios básicos: servicios financieros a largo plazo, atención a un gran número de clientes, enfoque a los más pobres y autosuficiencia y sostenibilidad.

13 (CGAP, 2015).

${ }^{14}$ Los indicadores propuestos en este trabajo han sido aplicados, en otros países y realidades, por autores como (Lewis, 2008), (Lauer, 2008) (Banerjee, Duglo, Glennester and Kinnan, 2014).
}

REVESCO No 123 - Primer Cuatrimestre 2017 - ISSN: 1885-8031 - www.ucm.es/info/revesco 
misión social de las instituciones se puede medir a través del promedio de los préstamos y de su evolución. Si este dato aumenta considerablemente puede ser porque la institución se esté moviendo hacia nuevos segmentos de clientes que probablemente no son tan pobres o incluso esté atendiendo a personas que ya cuentan con su propio negocio (Mesland, 2011).

c) Créditos menores de 400 dólares USA. Este indicador está relacionado con el anterior porque los pequeños créditos suelen ser un indicio de que las instituciones están atendiendo a una población más vulnerable. Población con menos recursos es capaz de implementar un micronegocio, generalmente informal, con una menor cantidad de dinero (Mesland, 2011).

d) Destino de los créditos. A raíz de la incursión de IMF reguladas se observo un cambio en el destino de los créditos. En un principio las IMF estaban más orientadas a la creación de micronegocios enfocados al comercio o al sector agrario (la mayoría de ellas eran informales). Con la aparición de las IMF reguladas en el sector microfinanciero, que tenían que tener ratios de rentabilidad adecuados, se modifico en cierta medida el destino de los créditos y fue orientándose hacia las pequeñas y medianas empresas.

e) Presencia de las ONG en el mundo rural. Otra característica propia de las microfinanzas es la atención a la población que vive más alejada del sector financiero tradicional, en este sentido se han ubicado y siguen operando áreas rurales (Zhang et al, 2006). Las organizaciones pioneras en el sector, se ubicaron en el medio rural porque consideraron que allí vivía la población más desfavorecida. En el caso de Perú el $19,1 \%$ de la población que vive en zonas urbanas es pobre frente a un 54,2\% de pobres que vive en las zonas rurales. Analizando los datos de pobreza extrema observamos que la brecha entre ambas zonas es aún mayor, dado que el 2,5\% población que vive en las áreas urbanas se encuentra en pobreza extrema frente al 23,3\% de población en extrema pobreza en el medio rural (Informe PNUD, 2010).

En el presente documento se ha analizado el periodo de tiempo comprendido entre los años 2005 y 2013. En ese sentido, se intentará hacer un análisis longitudinal (de los distintos indicadores sociales) entre el periodo de tiempo 2005 a 2013. No existen cifras oficiales anteriores al año 2005. Los datos se han extraído de los informes publicados por COPEME, 
Mix market y $\mathrm{SBSB}^{15}$. El número de $\mathrm{ONG}$ ha variado en este periodo, pasando de 22 en el año 2005 a 13 en el 2013. Por lo tanto, y dependiendo del año analizado, el número de ONG varía a lo largo del estudio. En cuanto a la evolución de las EDPYME también ha descendido el número que operan en el sector microfinanciero en Perú, pasando de 14 en el año 2005 a 8 en el año 2014 (Mix Market, 2015) (COPEME, 2014).

\subsection{Atención centrada en la mujer}

Son muchos los autores que argumentan que la pobreza repercute especialmente sobre la mujer. Es lo que se ha denominado "feminización de la pobreza" (Pearce, 1978; Hartman, 1990 y 1999). Esta situación se agrava por las mayores dificultades que tienen las mujeres para incorporarse al mercado laboral especialmente al mercado formal (Hardy y Hazelrigg, 1993; Choudhury y Leonesio, 1997; Hanson, 2009).

Por estas razones, desde su origen el sector microfinanciero ha mostrado gran interés por la atención a la mujer (Mody, 2000). Diferentes estudios han demostrado que el aumento de los ingresos de la mujer hace que se mejoren los niveles nutricionales de sus familias y la educación de los hijos y que se reduzca la natalidad (Panjaitan-Driodasuryo y Cloud, 1999; Hason, 2009). Una alimentación más completa o las mejoras realizadas en las casas gracias al microcrédito repercute, además de modo indirecto en la salud de los niños (Deloach y Lamanna, 2011, Syed y Naeem, 2012). Por último, las mujeres con acceso al crédito aumentan su poder en la toma de decisiones intrafamiliares (Ashraf et al., 2006). Parece, en resumen, que el acceso al crédito genera el "empoderamiento" de la mujer siempre que se combine el microcrédito con otras políticas (Holvoet, 2004).

En esta línea las ONG peruanas están atendiendo, en su mayoría, a mujeres (véase la Figura 1). El porcentaje de prestatarias (mujeres) en la cartera de las ONG ha venido oscilado en el periodo de estudio entre un 70 y un 90\%. La excepción son las ONG Fondesurco y Fovida que presentan un porcentaje más bajo especialmente en el año 2013 con alrededor de un $60 \%$ de prestatarios mujeres (COPEME, 2013).

${ }^{15}$ Algunos datos se han obtenido contactando directamente con las ONG. 
Figura 1. Porcentaje femenino entre prestatarios de las ONG, 2005-2013

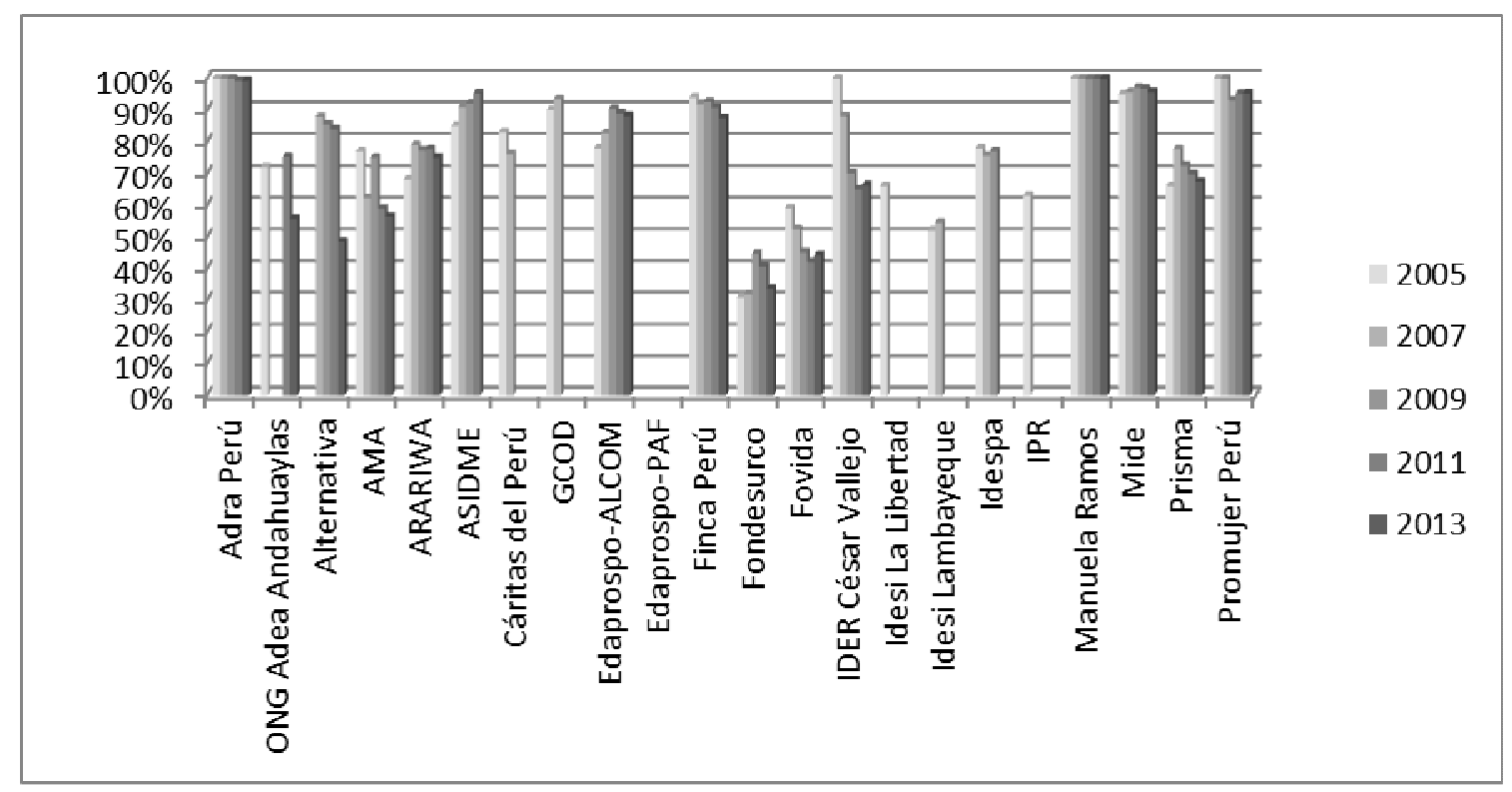

Fuente: Elaboración propia a partir de datos de COPEME 2005-2013

En el caso de las EDPYME la mayoría de estas instituciones contaban con un porcentaje de mujeres en torno al $50 \%$ prácticamente en todo el periodo analizado (20052013). Sólo en el caso de la EDPYME Solidaridad se aprecia un descenso significativo en el porcentaje de mujeres que paso de un $80 \%$ en el año 2005 a un 60\% en el año 2013. Tal y como se desprende de la información proporcionada por las instituciones ${ }^{16}$ no se aprecia que entre sus objetivos exista un especial interés por atender a las mujeres sino en la población más vulnerable ( sin distinción de sexo).

\footnotetext{
${ }^{16}$ Información obtenida a través de las páginas web de las EDPYME.
} 
Figura 2. Porcentaje femenino entre prestatarios de las EDPYME, 2005-2013

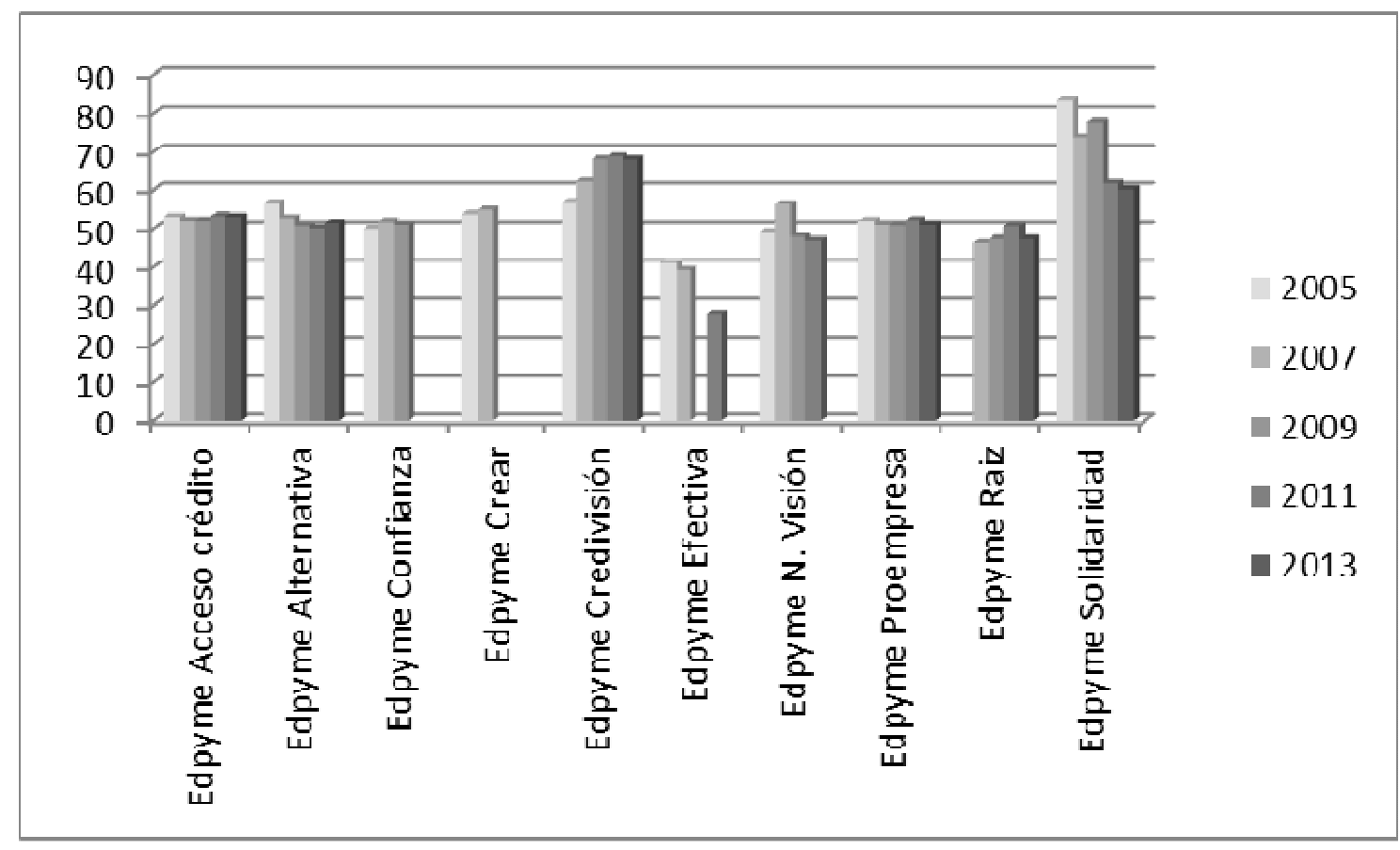

Fuente: Elaboración propia a partir de datos de COPEME 2005-2013

\subsection{Crédito promedio}

En el año 2013 en 11 de las 13 ONG analizadas el crédito promedio otorgado por las ONG estaba por debajo de los 900 dólares USA. Sólo en 2 de las 13 ONG, Fovida y Fondesurco, la media de los créditos otorgado era superior (1500 y 3600 dólares USA respectivamente en 2013). Estas dos organizaciones utilizan una metodología de crédito individual. En contraposición, 5 de las 13 ONG analizadas otorgaron en 2013, de media, créditos por debajo de los 350 dólares USA (Figura 3). Una de las razones que pueden explicar este reducido monto es la metodología crediticia de las ONG basada en los préstamos grupales o en bancos comunales, en contraste con las instituciones microfinancieras reguladas más enfocadas a la metodología individual ${ }^{17}$. Este resultado es coherente pues la metodología grupal es la más utilizada en zonas rurales o en pequeños pueblos (Lavoie et al., 2011). Algunos estudios realizados en países como la India constatan las ventajas de la metodología grupal para las mujeres pues mejoran su relación con la comunidad a través de las reuniones del grupo (Lejano y Shankar, 2013).

\footnotetext{
${ }^{17}$ Generalmente la metodología crediticia de grupos solidarios suele llevar implícito créditos de pequeños montos donde todos los miembros del grupo son solidarios de estos créditos. En este sentido esta metodología no suele estar vinculada a grandes créditos porque su orientación es la población más vulnerable que crea microempresas (informales).
} 
Figura 3. Crédito promedio en las ONG, 2005-2013

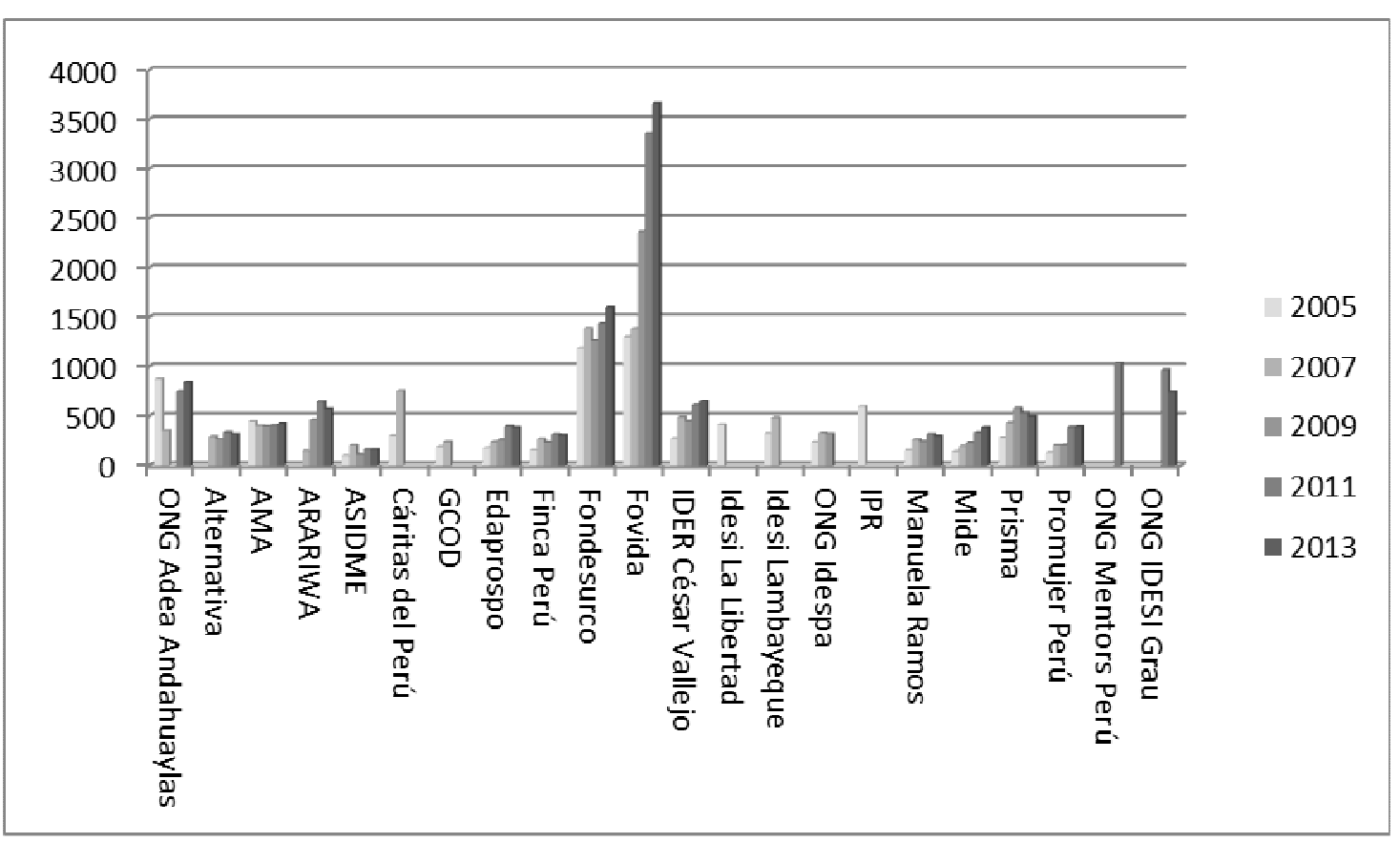

Fuente: Elaboración propia a partir de datos de COPEME, 2005-2013.

En cambio en el caso de las EDPYME la metodología crediticia está basada en créditos individuales en prácticamente todas las instituciones en todo el periodo analizado. Es por ello, el crédito promedio es algo mayor que en las ONG y rondaba los 1400 dólares USA en el año 2013 por encima de esta media están dos instituciones Acceso al Crédito y Proempresa que presentaron un crédito promedio cercano a 3000 dólares. Sin embargo, no ha sido siempre así porque en el año 2005 el crédito promedio de estas instituciones rondaba los 900 dólares USA incluso algunas instituciones como Acceso al Crédito y Proempresa presentaban datos por debajo de esta media, alrededor de 500 dólares USA y algo más de 800 dólares USA, respectivamente. 
Figura 4. Crédito promedio en las EDPYME, 2005-2013

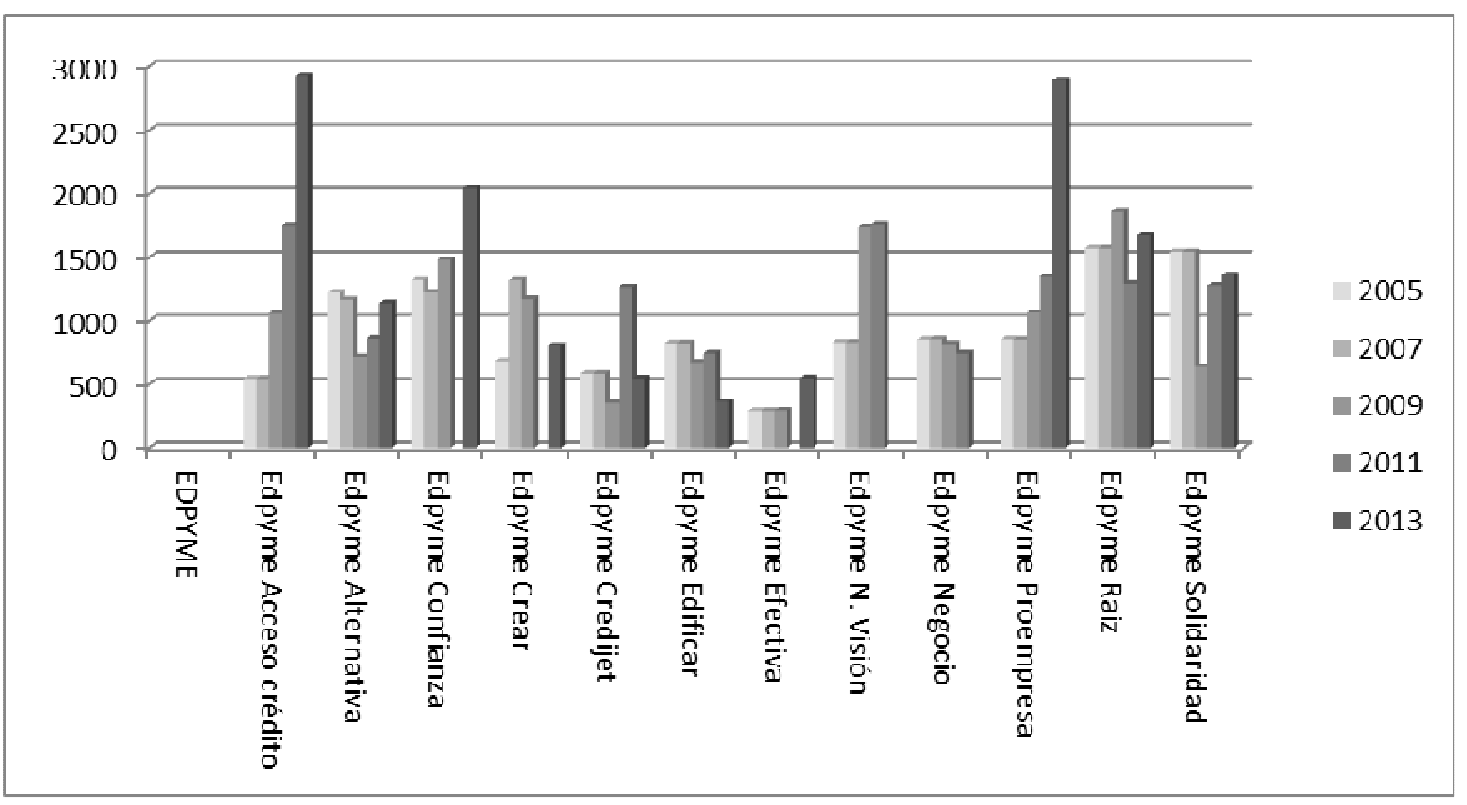

Fuente: Elaboración propia a partir de datos de COPEME, 2005-2013.

\subsection{Créditos menores de 400 dólares USA ${ }^{18}$}

Otorgar pequeños montos de dinero en forma de crédito debería significar un mayor alcance, puesto que los recursos de las ONG estarían siendo distribuidos entre un mayor número de prestatarios. A esto hay que añadir que, aquellos que demandan pequeñas cantidades suelen ser las personas más vulnerables que con pequeñas cantidades de dinero son capaces de crear micronegocios con carácter informal.

Siguiendo este razonamiento, un buen número de las ONG microfinancieras peruanas estarían preocupadas por el alcance pues en el año 2013 entre el 60-80\% de los créditos otorgados fueron menores a 400 dólares USA en 8 de las 13 ONG analizadas. Otro dato interesante es que los créditos de menores montos parecen estar vinculados al corto plazo, plazo que osciló, de media, entre 4 y 12 meses en el año 2013. Este dato no ha variado prácticamente durante el periodo de 2005 a 2013. Por último, también es importante el hecho de que el número de prestatarios ha aumentado durante este periodo de estudio, lo que podría implicar que los pequeños créditos están siendo destinados a nuevos clientes.

\footnotetext{
${ }^{18}$ No se han podido encontrar datos de las EDPYME sobre los créditos concedidos por estas instituciones por debajo de 400 dólares. Sin embargo, se ha incluido este indicador por ser uno de los más importantes en el estudio del impacto y la atención a los más vulnerables en el sector microfinanciero (CGAP, 2015).
} 
Figura 5. Créditos con montos menores de 400 dólares USA en las ONG, 2005-2013

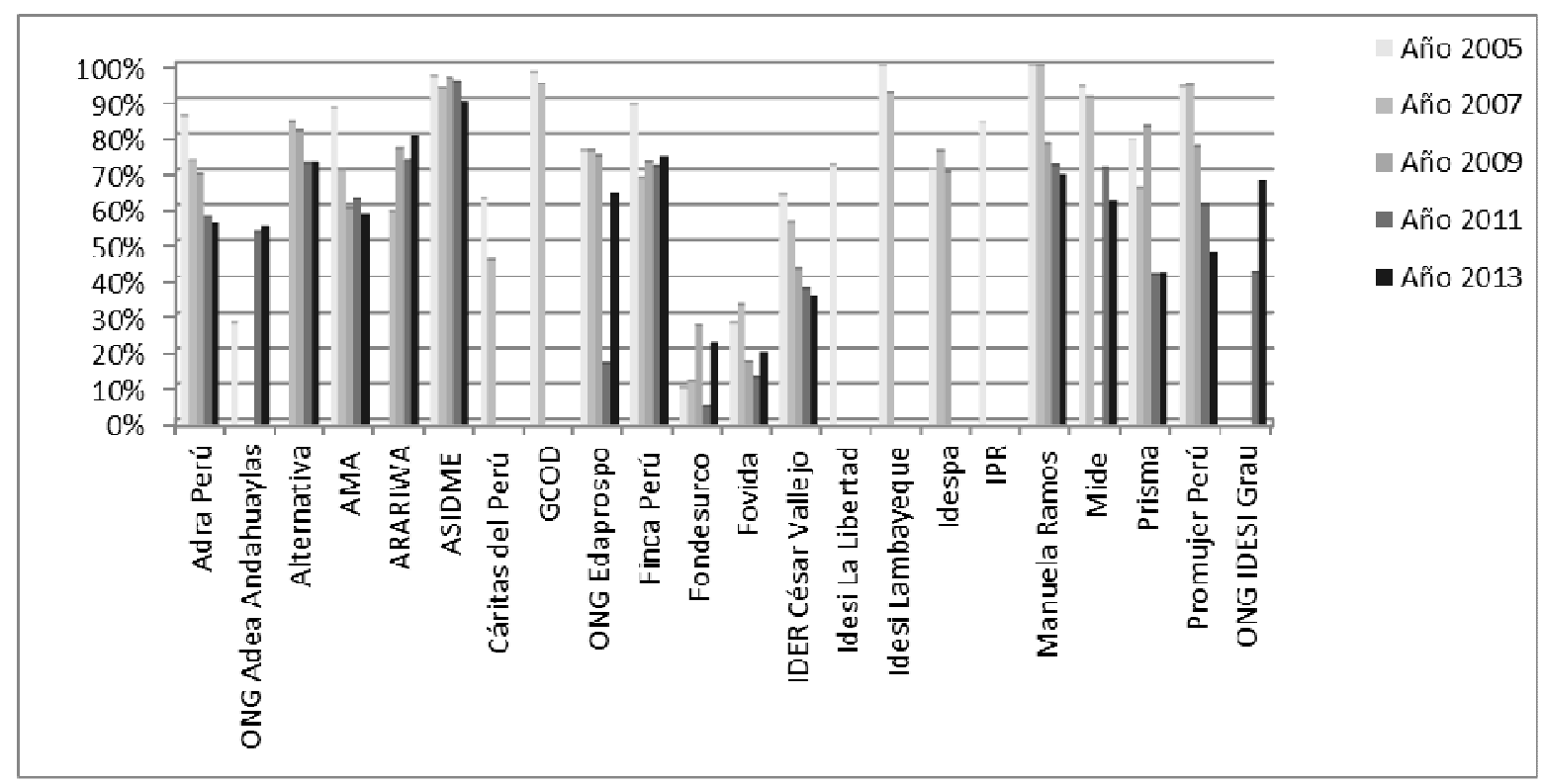

Fuente: Elaboración propia a partir de los datos de COPEME, 2005-2013

Tal y como se apuntó anteriormente en el caso de las EDPYME no se han encontrado datos sobre los créditos otorgados por estas instituciones de montos inferiores a los 400 dólares USA ${ }^{19}$.

\subsection{Destino final del préstamo}

Del total de los créditos otorgados por las ONG un porcentaje relativamente alto ha ido a parar a sectores como el comercio (figura 6). No hay que olvidar que buena parte de las mujeres pobres de Perú trabajan en actividades relacionadas con el mercado informal como por ejemplo la venta en la calle, preparación de comidas, trabajos manuales, limpieza, etc (Hason, 2009). Tal y como aparece en el siguiente gráfico los porcentajes de créditos dedicados al comercio son altos en general en todas las ONG siendo Promujer, Manuel Ramos, Finca y Andra Perú las que presentan porcentajes en torno al 70\% en todo el periodo, en cambio otras organizaciones como Fondesurco o Fovida mantienen porcentajes de crédito en todo al $20 \%$ dedicados al comercio. Estas dos últimas organizaciones se han orientado a los préstamos agropecuarios (de media en este periodo el $50 \%$ de sus préstamos fueron destinados a este sector).

\footnotetext{
${ }^{19}$ No se ha encontrado información a este respecto en fuentes como COPEME, Mix Market o en la web del Banco Central Peruano.
} 
Figura 6. Porcentajes de créditos concedidos para el comercio en ONG, 2005-2013

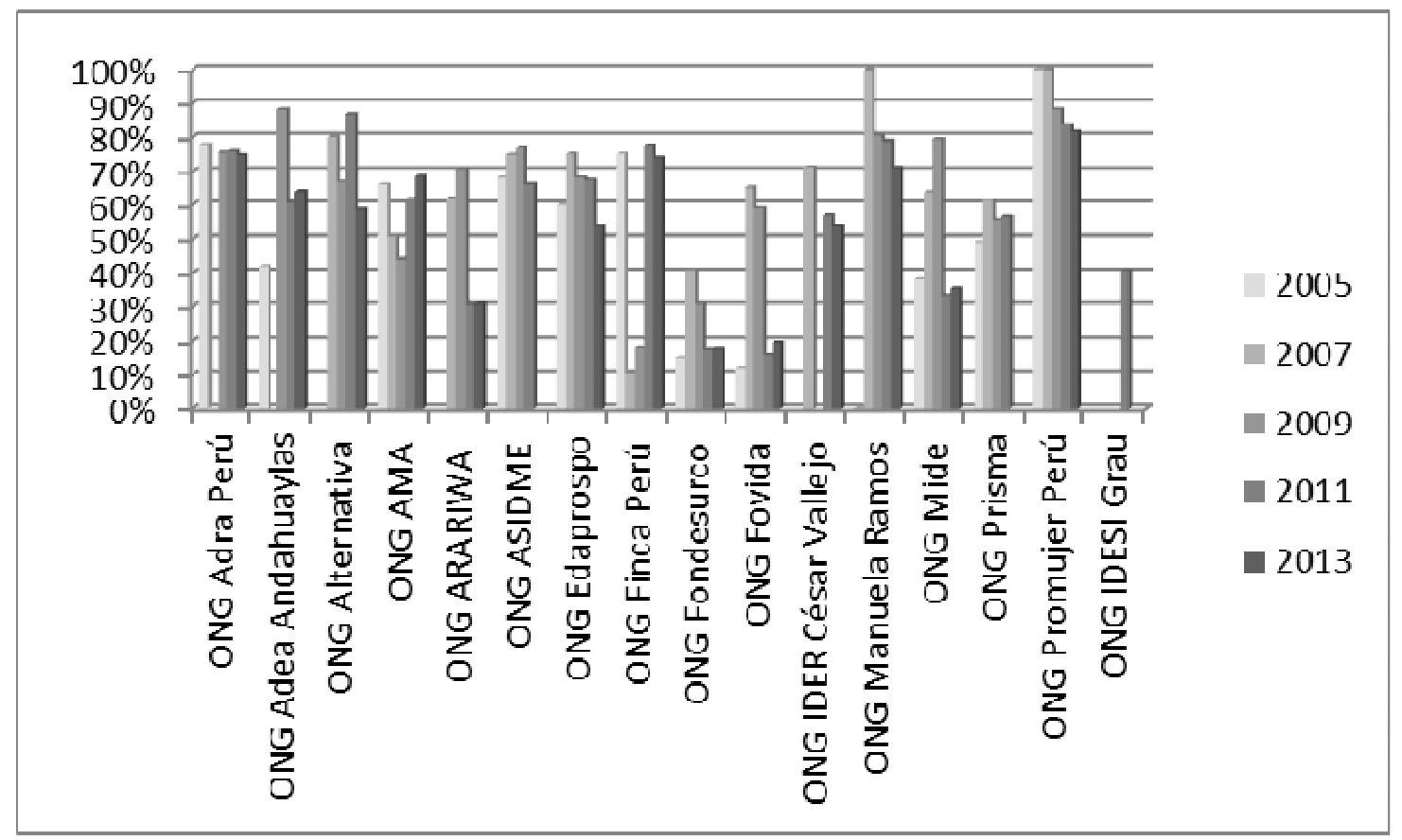

Fuente: Elaboración propia a partir de datos de COPEME, 2013.

En el año 2005 en prácticamente todas las EDPYME el porcentaje de préstamos dedicados al comercio era superior al 50\% y algunas instituciones como Raíz, Confianza, Crear o Efectiva incluso el porcentaje ascendían a un 70\%. Sin embargo, en el año 2013 la mayoría de las instituciones han ido cambiando el destino hacia otros sectores como servicios siendo especialmente significativo el caso de la EDPYME Acceso al crédito que destinó el 100\% de sus préstamos al servicio en el 2013 cuando en el 2005 el 69\% de sus créditos se destinaba al sector comercio. 
Figura 7. Porcentajes de créditos concedidos para el comercio en EDPYME, 2005-2013

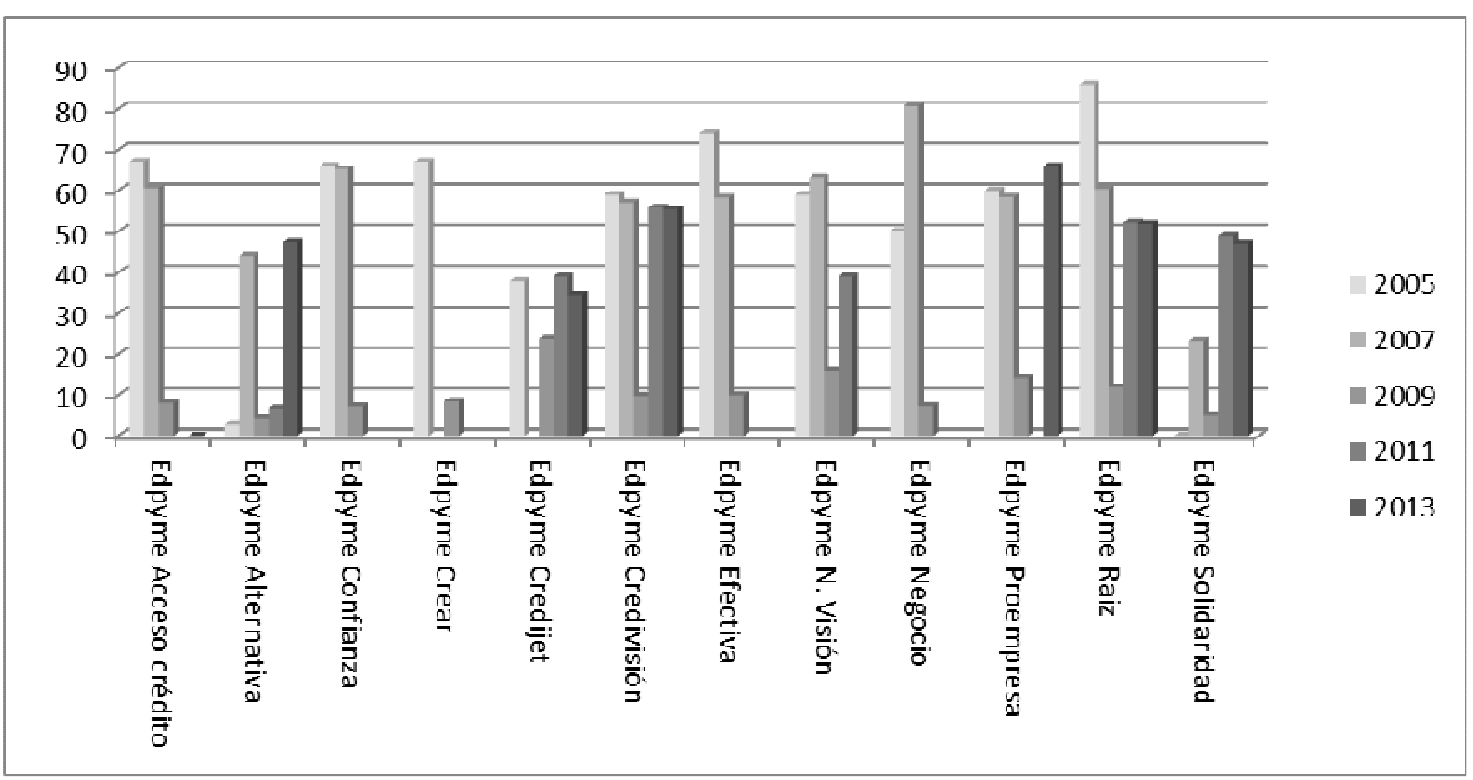

Fuente: Elaboración propia a partir de datos de COPEME, 2013.

Desde el año 2005 hasta el 2013 la mayoría de los prestatarios de las ONG analizadas han obtenido préstamos que se han destinado a microempresas (figura 8). Sólo algunas ONG como Manuel Ramos durante los dos últimos años analizados (2011 y 2013) no han destinado préstamos a microempresas o pequeñas empresas porque la mayoría se destinaron a consumo. No podemos olvidar que en América Latina los préstamos al consumo están apareciendo de forma cada vez más significativa en el sector microfinanciero en los últimos años (CGAP, 2001; Yancari, 2009; Karlan y Zinman, 2012). 
Figura 8. Porcentaje de créditos dedicados a microempresas y pequeñas empresas en ONG, 2005-2013

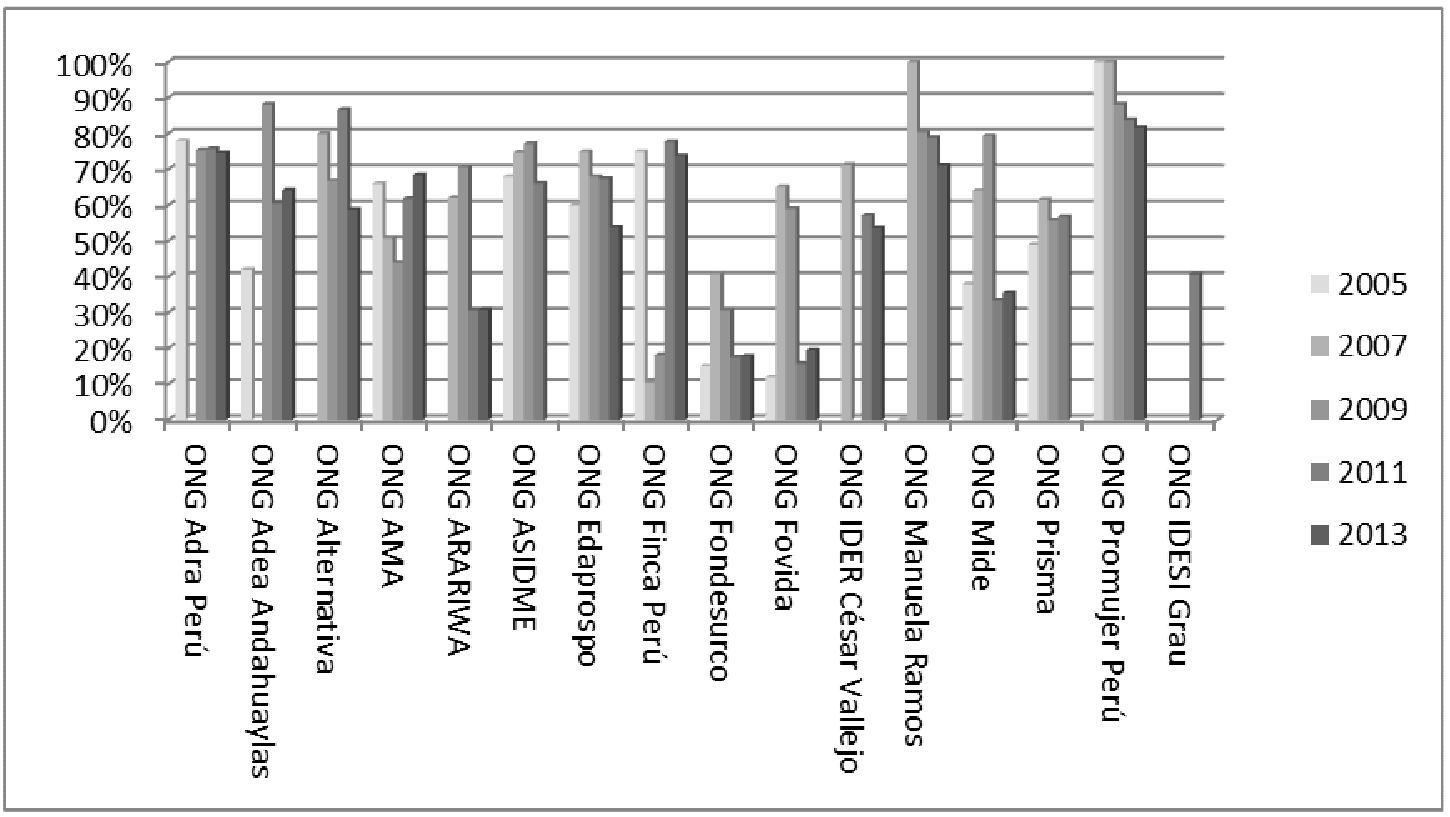

Fuente: Elaboración propia a partir de los datos de COPEME, 2005-2013.

En cuanto a los porcentajes de créditos destinados a la microempresas o pequeña empresa las EDPYME muestran datos divergentes. Algunas parece que con el paso del tiempo han ido dejando a un lado los créditos destinados a financiera microempresas o pequeñas empresas para financiar consumo o empresas medianas. Este es el caso de la EDPYME Acceso que presentaba un porcentaje de $94 \%$ de créditos destinados a las microempresas en el año 2005 y paso a un 28,4\% en el año 2013. Pero, por otro lado están aquellas EDPYME que han mantenido porcentajes altos de atención a la microempresa a lo largo de todo el periodo como es el caso de las EDPYME Credivisión (con un porcentaje del 95\% en el año 2005 y 87\% en el 2013) o la EDPYME Solidaridad (100\% en el año 2005 y 71,9\% en el año 2013). 
Figura 9. Porcentaje de créditos dedicados a microempresas y pequeñas empresas en EDPYME, 2005-2013

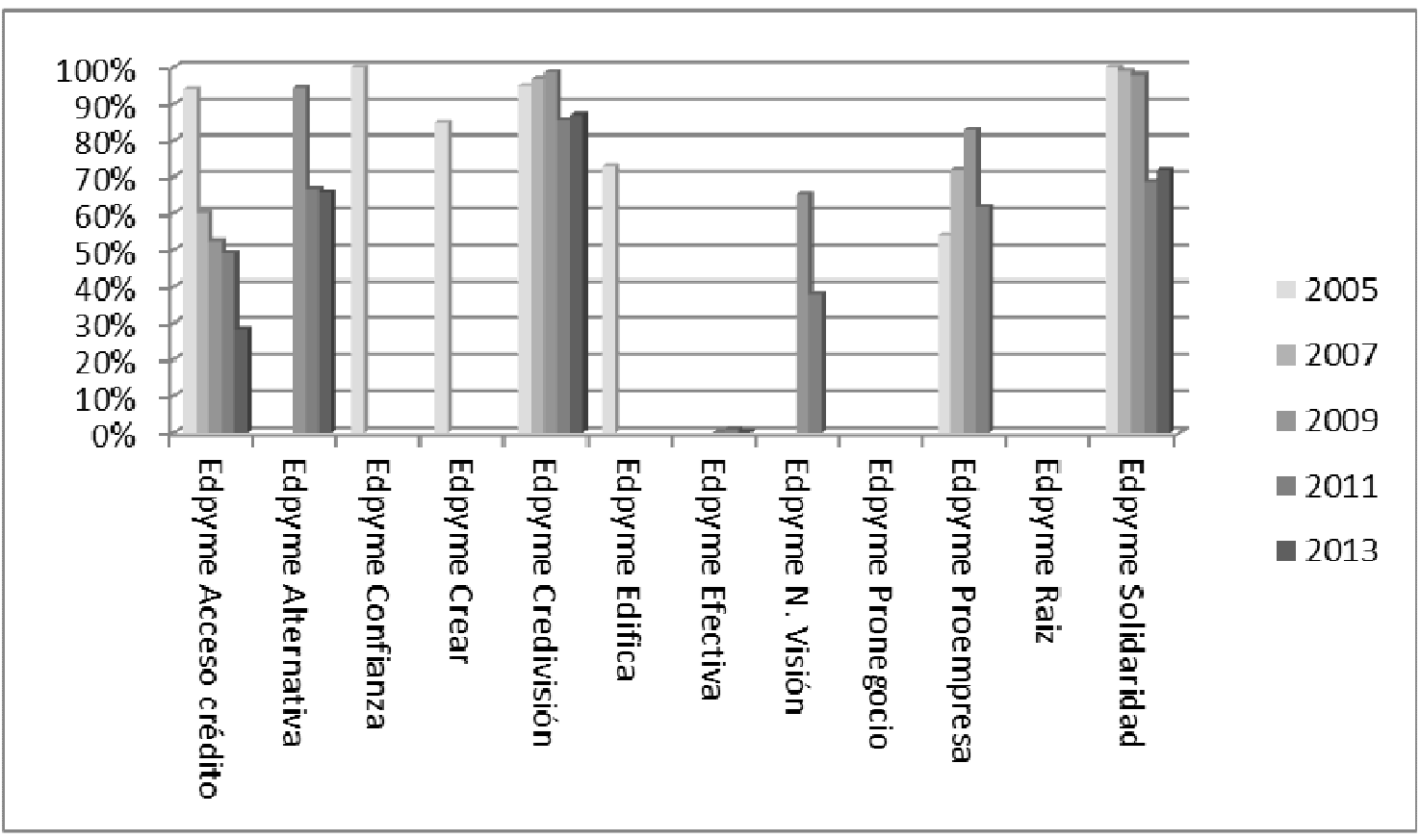

Fuente: Elaboración propia a partir de los datos de COPEME, 2005-2013.

\subsection{Presencia en el medio rural}

En Perú el 60,3\% de las personas pobres del país viven en el medio rural. En pobreza extrema se halla el 27,8\% de las personas que viven en Perú en zonas rurales frente a sólo un 2,8\% de los que viven en el medio urbano (INEI, 2010). En general es además en el medio rural donde existe una mayor desigualdad de género (Ganka, 2012). En Perú los datos muestran una realidad dura para las mujeres del medio rural, un 56,2\% no recibe ingresos por su trabajo (Ministerio de la Mujer y Desarrollo Social Perú, 2009) y un 33\% son analfabetas (frente a un 10\% de analfabetos hombres) (AECID, 2011).

De las trece ONG peruanas, nueve se crearon para atender a la población más desfavorecida del medio rural y siguen vinculadas a este medio, las otras cuatro restantes operan exclusivamente en el ámbito urbano (desde su origen $)^{20}$.

En cuanto a las EDPYME sólo dos de las ocho operan en el medio rural. Éstas EDPYME que operan en el medio urbano lo hicieron durante todo el periodo analizado, la

\footnotetext{
${ }^{20}$ Este dato ha sido obtenido en las distintas web de las ONG o en conversaciones con ellas.
} 
mayoría de ellas se crearon para atender a personas desfavorecidas que viven en el entorno urbano.

\section{DISCUSIÓN}

El presente trabajo estudia si las ONG microfinancieras peruanas han sido capaces realmente de mantener su misión social en un mercado enormemente competitivo, y si por tanto ha estado justificada su negativa, en los casos en que así ha sido, a convertirse en instituciones reguladas.

A esta cuestión se responde examinando una serie de indicadores. El primero investiga cuál es la población objetivo a la que se dirige la actividad de estas ONG. Aunque resulta difícil establecer una caracterización precisa de la población objetivo, las ONG parecen seguir dando prioridad al medio rural donde vive en Perú la población más pobre. Y más en concreto a la mujer que habita en estas zonas. Con ello no hacen sino mantener lo que puede considerarse su seña de identidad, pues una buena parte de las ONG que hoy operan en Perú comenzaron su andadura en la década de los noventa atendiendo a mujeres que vivían en el medio rural. Comparando este dato con el de las EDPYME nos encontramos con importantes diferencias, dado que estas instituciones operan (la mayoría desde su creación) en el medio urbano y su población objetivo no está directamente vinculado al género.

En segundo lugar, la política crediticia puede ser un rasgo distintivo con respecto al resto de instituciones que operan en el sector. En efecto parece serlo pues muchas de las ONG están priorizando el otorgamiento de créditos reducidos, créditos que sus prestatarios destinan, en la mayoría de los casos, a pequeñas actividades comerciales o agropecuarias. El reducido monto y plazo de los microcréditos otorgados se puede además explicar por la metodología grupal o de banco comunal (frente a la metodología individual que suelen implementar las IMF reguladas). En el caso de las EDPYME el crédito promedio no baja de los 900 euros a lo largo de todo el periodo estudiado. Además, el crédito promedio ha ido incrementándose prácticamente en todas las EDPYME a lo largo del periodo analizado. Algo que va en línea con la metodología crediticia utilizada que es la individual, con los montos del crédito que van aumentando con el paso de los años y con el destino de los créditos que empezó siendo la microempresa pero parece que se está empezando a dar prioridad a las medianas empresas. 
Otra característica que distingue a las ONG es el hecho de que su labor va más allá de la mera concesión del microcrédito. Siguen desarrollando programas o actividades que conllevan unos beneficios difíciles de cuantificar pero que tienen un indudable impacto sobre la vida de los prestatarios, sus familias y entorno. Aunque no existe demasiada información sobre estos programas, sí se conoce que las ONG microfinancieras peruanas desarrollan programas no vinculados directamente al microcrédito (talleres formativos sobre salud o educación de los hijos) y otros que sí lo están, como por ejemplo cursos de capacitación orientados al emprendimiento que permiten a los futuros prestatarios tener una mayor seguridad o confianza al emprender un micronegocio. Esto es interesante pues muchos autores destacan la importancia de una adecuada formación que permita a los prestatarios enfrentarse al emprendimiento de una actividad empresarial (Jamali y Keshishian, 2009; Valenzuela Ramírez, 2011; Al Mamun et al., 2012). Debe además considerarse que los prestatarios del microcrédito no siempre tienen vocación para emprender un negocio (Saad, 2013) y que se hace, por tanto, muy recomendable que los prestatarios reciban capacitación adecuada a su perfil, al tipo de microempresa y a su nivel educativo. En el caso de las instituciones que se han regulado no llevan a cabo actividades más allá de las propias derivadas del crédito. En realidad, estas instituciones tienen una estructura y unos objetivos que parecen estar más cercanos a los bancos que a las ONG. Si bien es cierto, que algunas de las EDPYME tenían actividades más allá del crédito o el ahorro cuando eran ONG. A cambio la transformación en instituciones reguladas les ha permitido captar ahorro frente a las ONG que no pueden hacerlo.

En resumen, parece que las ONG, con luces y con sombras, están manteniendo su identidad en un escenario complejo marcado por el crecimiento del sector, la aparición de nuevos agentes y un marco legislativo que fomenta la competitividad del mercado. Quizá la clave radica en que operan en su mayoría en zonas rurales donde se siente menos la competencia y también en que desarrollan actividades sociales que crean un vínculo más estrecho con sus clientes. ¿Seguirá siendo esto así en el futuro? ¿Podrán seguir operando las ONG sin desviarse de su misión social en los próximos años? ¿Serán capaces de aguantar las presiones en un mercado cada vez más competitivo? Es difícil responder a estas cuestiones. Otros agentes, muy en concreto los bancos, parecen estar aumentando sus ratios de eficiencia y de manejo del riesgo, lo que les permite bajar los tipos de interés y, en último término, incrementar su alcance (Portocarrero et al., 2012). Además, las donaciones externas son cada vez más reducidas y condicionadas a la consecución de objetivos. En cualquier caso, si estas 
tendencias provocaran la desaparición de las ONG, su hueco, pequeño en cuanto a portafolio y número de prestatarios pero grande en cuanto a función social, sería difícil de cubrir.

\section{BIBLIOGRAFÍA}

AECID (2011) Agenda para la igualdad entre hombres y mujeres 2011-2015. Editado por la Agencia Española de Cooperación Internacional al Desarrollo y por el Ministerio de la Mujer y el Desarrollo Social de Perú, Madrid-Lima, España, Perú.

AGBEIBOR, Jr. W. (2006) Pro-poor economic growth: Role of small and medium sized enterprises. Journal of Asian Economics, № 17, Vol. 1, pp. 35-40.

AGHION, M. y MORDUCH, J. (2005) The economic of micro-finance. Editado por MIT Press, Cambridge, Reino Unido.

ALVES, S.D.M y SOARES, M.M. (2006) Microfinanças: Democratizaçao do Crédito no Brasil, Atuaçao do Banco Central. Editado por el Banco Central de Brasil.

ARMENDÁRIZ DE AGHION, B. y MORDUCH, J. (2005) The economics of microfinance. Cambridge: MIT Press, cop.

ASHRAF, N., KARLAN, D. y YIN, W. (2006) Female Empowerment: Impact of Commitment Savings Product in the Philippines. Quartely Journal of Economic, $\mathrm{N}^{\mathbf{0}} 121$, Vol. 2, pp. 635-672.

BARNERJEE, A. and DUFLÓ E. (2010) Giving Credit Where it is due?. Journal of Economic Perspectives, № 24, Vol. 3, pp. 61-80.

CANIELS, M.C.J, ROMIJN, H.A y DE RUIJTER-DE WILDT, M. (2006) Can business development services practitioners learn from theories of innovation and services marketing?. Development in Practice, № 16, Vol. 5, pp. 425-440.

CGAP (2001) Comercialización y desvío de la misión. La transformación de las microfinanzas en América Latina. Estudios Especiales CGAP, Washington, DC, EE.UU.

CGAP (2005) Bancos comerciales y microfinanzas: Evolución de los modelos que han dado buenos resultados. Enfoque de CGAP, 28, junio. Washington, DC, EE.UU.

CGAP (2015) The Universal Standars for Social Performance Management. Acceso en: http://sptf.info/spmstandards/universal-standards.

CHRISTEN, R.P., LYMAN T. y ROSENBERG, R. (2003) Microfinance Consensus Guidelines: Guiding Principles on Regulation and Supervision of Microfinance. Editado por CGAP. Washington, EE.UU. 
CHOULDHURY, S. y LEONESIO, M. (1997) Live-cycle aspects of poverty among older women. Social Security Bulletin, № 60, pp. 17-36.

CHU, M. (2010) Las microfinanzas: creación simultánea de impacto social y valor comercial. Debates IESA, 3 (XV).

CLARK, J. (1991) Democratising Development. Editado por Kumarian Press, West Hartford, CT.

COPEME (2005) Reporte anual del Consorcio de organizaciones privadas de promoción de la micro y pequeña empresa. Recuperado el 10 de abril de 2011 de www.copeme.org.pe.

COPEME (2007) Reporte anual del Consorcio de organizaciones privadas de promoción de la micro y pequeña empresa. Recuperado el 10 de abril de 2011 de www.copeme.org.pe.

COPEME (2009) Reporte anual del Consorcio de organizaciones privadas de promoción de la micro y pequeña empresa. Recuperado el 10 de abril de 2011 de www.copeme.org.pe.

COPEME (2012) Reporte anual del Consorcio de organizaciones privadas de promoción de la micro y pequeña empresa. Recuperado el 25 de febrero de 2011 de www.copeme.org.pe.

COPEME (2013) Reporte anual del Consorcio de organizaciones privadas de promoción de la micro y pequeña empresa. Recuperado el 20 diciembre de 2015 de www.copeme.org.pe.

COPEME (2014) Reporte anual del Consorcio de organizaciones privadas de promoción de la micro y pequeña empresa. Recuperado el 20 diciembre de 2015 de www.copeme.org.pe.

CULL, R., DEMIGU“C-KUNT, A., y MORDUCH, J. (2007) Financial performance and outreach: A global analysis of leading microbanks. Economic Journal, № 117, Vol. 517, pp. 107-133.

DELOACH St. y LAMANNA E. (2011) Measuring the Impact of Microfinance on Child Health Outcomes in Indonesia. World Development, No 10, Vol. 39, pp. 1808-1819.

DALEY-HARRIS, S. (2011) State of the Campaing Report, 2011. Editado por Microcredit Summit Campaign.

DE LA TORRE, A., GOZZI, J.C. y SCHMUKLER, S.L. (2007) Innovation experiences in Access to finance: market friendly roles for the visible hand. World Bank Policy Research Working Paper, 4326.

DINIZ, E., POZZEBON M., JAYO, M. y ARAUJO, E. (2008) The Role of Information and communication Technologies (ICT) in Improving Microcredit: The Case of Correspondent Banking in Brazil. Documento presentado en PICMET 2008 Proceedings, 27-31 July, Cape Town, South Africa. 
EBENTREICH, M. (2009) Microfinance Regulation in Peru: Current State, Lessons Learned and Prospects for the Future. Microfinance Gateway Resource Center, No 4. Recuperado el 15 de abril de 2012 de www.microfinancegateway.com/file/25523filePeru.pdf.

FERNÁNDEZ, B. (2006) Microfinanzas en los países del sur: surgimiento y características generales. In: Á. GALINDO and M. DE LA CUESTA, eds, Las microfinanzas, instrumento de desarrollo entre Europa e Iberoamérica. 2006 edn. Salamanca: Publicaciones Universidad Pontificia de Salamanca, pp. 45-67.

FISZBEIN, A. y LOWDER, P. (1999) Working together for a change: Government, civic and business partnerships for poverty reduction in Latin American and the Caribbean. Editado por el Banco Mundial, Washington, D.C., EE.UU.

GANKA I. (2012) Improving Women and Family's Health through Integrated Microfinance, Health Education and Promotion in Rural Areas. Journal of Sustainable Development, ${ }^{\circ}$ 5, Vol. 5, pp. 32-45.

GOLDBERG, N. (2005) Measuring the impact of microfinance: taking stock of what we know. Grameen Foundation USA. Recuperado el 5 de marzo de 2012 de www.grameenfoundation.org.

GOLDBERG N. y KARLAN D. (2006) The Impact of Microfinance: A Review of Methodological Issues. Financial Access Initiative and Innovation for Poverty Action. Recuperado el 5 de marzo de 2012 de www.financialaccess.org.

GUTIÉRREZ J. y GOITISOLO, B. (2011) Profitability and social performance of microfinance institutions: Empirical evidence of relations between different variable. Revista de Economía Mundial, No 27, pp. 189-214.

HARDY, M.A y HAZELRIGG, L.E. (1993) The gender of poverty in an aging population. Research on Aging, $\mathrm{N}^{\circ}$ 15, pp. 243-278.

HARTMAN, A. (1990) Aging as a feminist issue. Social Work, No 35, pp. 387-388.

HARPER, M. (2002) Grameen bank groups and self-help groups; what are the differences? Recuperado el 5 de abril de 2012 de www.microfinancegateway.org/content/article/detail/3249.

HELMS, B. (2006) Access for All: Building Inclusive Financial Systems. Editado por el Banco Mundial.

HISHIGSUREN, G. (2007) Evaluating mission drift in microfinance. Lessons for programs with social mission. Evaluation Review, $\mathrm{N}^{\mathrm{o}}$ 31, Vol. 3, pp. 203-260.

INEI (2010) Instituto Nacional de Estadística e Informática de Perú. Indicadores social y de género. Recuperado el 10 de abril de 2012 de 
http://www1.inei.gob.pe/web/PeruCifrasDetalle4.asp.

INFORME PNUD (2010) Tercer Informe de Naciones de cumplimiento de los ODM. Editado por PNUD.

JAMALI, D. y KESHISHIAN T. (2009) Uneasy Alliances: Lesson Learned form Partnerships between Businesses and NGOs in the context of CRS. Journal of Business Ethics, $\mathrm{N}^{\circ} 84$, pp. 277-295.

KARLAN D. y ZINMAN J. (2012) List randomization for sensitive behavior: An application for measuring use of loan process. Journal of Development Economics 98, pp. 71-75.

KHANDLER, S.R. (2005) Micro-finance and Poverty: Evidence Using Panel Data from Bangladesh. World Bank Economic Review, No 19, Vol. 2, pp. 263-286.

KHALILY, M.B., IMAM M.O. y KHAN, S.A. (2000) Efficiency and Sustainability of Formal and Quasiformal Microfinance Programs An Analysis of Grameen Bank and ASA en Rushidan I, Rahman y Shahidur R Kandker (eds). The Bangladesh Development Studies: an Special Issue on Microfinance and Development: Emerging Issue, $\mathrm{N}^{\mathrm{o}} 26$, pp. 103-146.

LACALLE, M., ed, 2008. Microcréditos y pobreza: de un sueño al Nobel de la Paz. Madrid: Turpial.

LAFOURCADE, A., ISERN, J., MWANGI, P., y BROWN, M. (2005) Overview of the outreach and financial performance of microfinance institutions in Africa. Microfinance Information Exchange (MIX). Recuperado 10 de abril de 2012 de www.ruralfinancenetwork.org/pubs/MIX\%20Africa_Data_Study.pdf.

LAUER, K. (2008) Transforming NGO MFIs: Critical Ownership Issues to consider. Occasional Paper, $\mathrm{N}^{\circ}$ 13. Editado por CGAP, Washington DC, USA.

LAVOIE F., POZZEBON, M. y GONZALEZ, L. (2011) Challenges for inclusive finance expansion: The case of CrediAmigo, a Brazilian MFI. Management International, $\mathrm{N}^{\mathrm{o}} 15$, Vol. 3, pp. 57-69,113-118.

LEJANO, R.P y SHANKAR, S. (2013) The contextualist turn and schematics of institutional fit: Theory and a case study from Southern India. Policy Sciences, № 46, pp. 83-102.

LEWIS, J.C. (2008) Microloan sharks. Stanford Social Innovation Review, summer: pp. 54-59 MAKITA, R. (2009) New NGI-Elite Relations in Business Development for the Poor in Rural Bangladesh. Voluntas, No 20, pp. 50-70.

MAMUN, A.A., DAIKALAM J y HUDA N. M. (2012) Examining the Effect of Amanah Ikhtiar Malaysia's Microcredit Program on Microenterprise Assets in Rural Malaysia. Asian Social Science, № 4, Vol. 8, pp. 25-42. 
MARBÁN, R. (2008) Estudio de los principales programas de microfinanzas desarrollados e implantados en el Sur de la India. Revista de Economía Mundial, № 18, pp. 255-266.

MARBÁN, R. (2011) The impact of microcredit on the life quality of women in the rural area in Andhra Pradesh (India). Asian-Pacific Social Science Review, No 11, Vol. 2, pp. 43-56.

MARBÁN, R. y DE PABLO, S. (2012) Las instituciones microfinancieras ante la crisis económica: La Fundación D-Miró como estudio de caso. Revista Sociedades Rurales, Producción y Medio Ambiente, № 23, Vol. 12, pp. 44-69.

MARULANDA, B. y OTERO M. (2005) The profile of microfinance in Latin America in 10 years: vision and characteristics. Editado por ACCION International. Boston, EE.UU.

MAYOUX, L. (2001) Tackling the Down Side: Social Capital, Women's Empowerment and Microfinance in Cameroon. Development and Change, $\mathrm{N}^{\circ}$ 32, Vol. 3, pp. 435-464.

MERLAND, R. and OYSTEIN, R (2010) Microfinance Mission Drift? World Development $\mathrm{N}^{\mathrm{o}}$ 1, Vol. 38, pp. 28-36.

MICROSCOPIO BID (2012) Microscopio Global sobre el entorno de negocio para las microfinanzas. Recuperado el 26 de febrero de 2013 de http://www5.iadb.org/mif/eses/portada/conocimiento/datadedesarrollo/microscopio.aspx.

MIX MARKET (2006) Benchmarking de las Microfinanzas en América Latina 2005. Editado por Microfinance Information Exchange. Washington, EE.UU.

MIX MARKET (2009) Benchamarking de las Microfinanzas en América Latina 2008. Editado por Microfinance Information Exchange, septiembre. Washington, EE.UU.

MIX MARKET (2010) Estadísticas Mix market. Recuperado el 5 de abril de 2012 de www.mix.market.org.

MIX MARKET (2012) Estadísticas Mix market. Recuperado el 26 de febrero de 2013 de www.mix.market.org.

MIX MARKET (2013) Estadísticas Mix market. Recuperado el 26 de febrero de 2013 de www.mix.market.org.

MIX MARKET (2015) Estadísticas Mix market. Recuperado el 20 de diciembre de 2015 en www.mix.market.org.

Ministerio de la Mujer y Desarrollo Social en Perú. Informe Mujer y Hombres en Situación de Pobreza: 2009-2010. Recuperado el 5 de abril de 2012 www.mimdes.gob.pe/files/DIRECCIONES/DGPDS/indicadores/mujeres_hombres_pobre za.pdf.

MODY, P. (2000) Gender Empowerment and Microfinance. Working Paper. Editado por Evans School, EE.UU. 
NAVAJAS, S. et al. (2006) Indicadores de Microfinanzas en América Latina: Rentabilidad, Riesgo y Regulación, Banco Interamericano de Desarrollo, Washington, D. C.

PANJAITAN-DRIODASURYO, R. y CLOUD K. (1999) Gender, Selft-Employment and Microcredit Programs. An Indonesian Case Study. The Quarterly Review of Economics and Finance, $\mathrm{N}^{\mathrm{o}} 39$, pp. 769-779.

PCR (2012) Informe sectorial del Pacific Credit Rating. Recuperado el 26 de febrero de 2013 de: www.ratingspcr.com/Sectorial\%20Microfinanzas-\%20Perú.pdf.

PEARCE, D.M. (1978) The feminization of poverty: Women, work and welfare. Urban \& Social Change Review, $\mathrm{N}^{\mathrm{o}} 11$, pp. 28-37.

PITT, M.M, KHANDKER, S.R, CHOWDHURY O.H y MILIMET D.L. (1998) Credit Programs for the Poor and the Nutritional Status of Children in Rural Bangladesh. Populations Studies and Training Center Working Paper, 98-01. Editado por R.I. Brown University.

PORTOCARRERO, F. (2000) La Oferta Actual de Microcrédito en Perú en F. Portocarrero, C. Trivelli y J. Albarado (2002). Microcrédito en Peru: Quiénes Piden y Quiénes Dan. Consorcio de Investigaciones Económica y Social, 13-84.

PORTOCARRERO, F.; BÉLANGER Ch. y PARADA M. (2012) Commercial bank and microfinance: Downscaling versus equitity investments in MFIs in Peru. Enterprise Development and Microfinance, $\mathrm{N}^{\circ}$ 23, Vol. 3, pp. 217-229.

POGGE, T. (2002) World Poverty and Human Right: Cosmopolitan Responsibilities and Reforms. Polity Press, Cambridge, Reino Unido.

RAFI, M. y MALLICK D. (2002) Group Dynamics in Development of the Poor: Experience from BRAC. Journal of Voluntary and Nonprofit Organizations, $\mathrm{N}^{\mathrm{o}} 13$, Vol. 2, pp. 165178.

ROBINSON, M. S. (2001) The Microfinance Revolution. Editado por el Banco Mundial y Open Society Institute.

ROY J. y CHOWDHURY, P.R. (2009) Public-private partnerships in micro-finance: Should NGO involvement be restricted? Journal of Development Economics, № 90, pp. 200-208.

ROODMAN, D. y MORDUCH, J. (2009) The Impact of Microcredit on the Poor in Bangladesh: Revisiting Evidence. Working Paper, 174, Central for Global Development. Recuperado el 10 de abril de 2012 de www.cgdev.org/content/publications/detail/1422302. 
SAAD, A. (2013) The Impact of Credit and Non-Credit Aspects on Self-Employment Profit: A Comparison of Microcredit Programs and Commercial Lenders in Rural Bangladesh. The Journal of Developing Areas, $\mathrm{N}^{\circ}$ 1, Vol. 47, spring.

SBS (2013) Estadísticas. Recuperado el 25 de febrero de 2013 de www.sbs.gob.pe/app/stats/EstadisticaBoletinEstadistico.

SCHREINER, M. (2002) Aspects of outreach: A framework for discussion of the social benefits of microfinance. Journal of International Development, № 14, pp. 591-603.

SYED F.E.H. (2012) Developing microfinance sector in Balochistan. Pakistan \& Gulf Economist, $\mathrm{N}^{\mathrm{o}} 31$, Vol. 11, pp. 70-72.

SYED F. E. y NAEEM, H. (2012) The impact of microfinance on social mobility, an empirical evidence from Pakistan. Interdisciplinary Journal of Contemporary Research in Business, № 3, Vol. 9, pp. 81-89.

UNICIRDAP (1999) United Nations Interagency Committee on Integrated Rural Development for Asia and the Pacific, 1992. Partners in Rural Poverty Alleviation: NGO Cooperation United Nations, New York, EE.UU.

VALENZUELA, I. (2011) Profundidad de alcance en un contexto de comercialización de las microfinanzas en el Perú, Economía, № 68, Vol. XXXIV, pp. 33-63.

YANCARI, J. (2009) Crisis y pobreza rural en América Latina: el caso de Perú. Documento de Trabajo $N^{\circ} 41$. Latin American Center for Rural Development (Rimisp), Santiago, Chile.

YU, X. (2011) Social enterprise in China: Driving forces, development patterns and legal framework. Social Enterprise Journal, No 7, Vol. 1, pp. 9-32.

ZHANG, J., LI X. y ROZELLE, S. (2006) Self-employment with Chinese-characteristics: The forgotten engine of rural China's growth. Contemporary Economic Policy, № 24, Vol. 3, pp. 446-458. 